\title{
A scientific note: Foragers deposit attractive scent marks in a stingless bee that does not communicate food location*
}

\author{
Elinor M. LICHTENBERG ${ }^{1}$, Michael HRNCIR ${ }^{2}$, James C. NIEH ${ }^{1}$ \\ ${ }^{1}$ University of California San Diego, Division of Biological Sciences, Section of Ecology, Behavior and Evolution, \\ 9500 Gilman Drive \#0116, La Jolla, CA 92093-0116, USA \\ ${ }^{2}$ Universidade de São Paulo, Faculdade de Filosofia, Ciências e Letras de Ribeirão Preto, Depto. de Biologia, Bloco 7 , \\ Avenida Bandeirantes 3900, CEP: 14040-901, Ribeirao Preto-SP, Brasil
}

Received 10 April 2008 - Revised 1 December 2008 - Accepted 5 December 2008

\section{Melipona quadrifasciata / stingless bee / scent mark / foraging / olfactory information}

Scent marking of profitable food sources improves foraging efficiency and helps social bees meet colony demands for unpredictable floral resources (Giurfa and Núñez, 1992). Sophisticated marking has evolved in the stingless bees (Apidae, Meliponini); several genera recruit nestmates to profitable food sources with scent signals (reviewed in Nieh, 2004). Scent cues such as "footprints" (Wilms and Eltz, 2008) can also facilitate navigation and orientation to rewarding parts of food patches. Scent marks may improve colonies' competitive ability, especially in the tropics, where social bee abundance and diversity are high. We assessed scent mark use by the stingless bee Melipona quadrifasciata. This species poorly communicates to nestmates the location of rich food sources (Jarau et al., 2000), thus could benefit from within-patch orientation information provided by attractive odor marks. However, its ability to deposit and use fieldbased information is not known.

We studied four Melipona quadrifasciata anthidioides colonies at the Universidade de São Paulo, Ribeirão Preto in July 2007, and JulyAugust 2008, using feeder choice tests (see, for example, Hrncir et al., 2004). To begin a trial, we allowed foragers trained to feed on $1.5 \mathrm{M}$ sucrose solution to recruit 15 nestmates not previously used in the experiment. The 15 bees freely fed at a "visited" feeder for $10 \mathrm{~min}$, during which we counted the number of visits. Next, we aspirated all bees and replaced the original apparatus with the visited and clean feeders on clean tripods, separated by $30 \mathrm{~cm}$.

Corresponding author: E.M. Lichtenberg, elichten@ucsd.edu

* Manuscript editor: Yves Le Conte
We then released the 15 bees at the nest entrance, and recorded the number of bees landing on each feeder for 30 minutes, controlling for local enhancement by only counting bees landing alone. Data were analyzed with R v.2.6.0. To meet parametric assumptions, we applied Anscombe's arcsine transformation to the proportion of bees landing on the visited feeder.

Foragers visited between 49 and 140 times, always more than the 40 visits required to attract $M$. seminigra foragers (Hrncir et al., 2004). M. quadrifasciata foragers did not use mandibular secretions as scent marks; unlike Kerr (1994) we never observed bees rubbing mouthparts on feeders. Neither preference for the visited feeder (ANOVA: $\mathrm{F}_{3,10}=$ $0.53, P=0.67)$ nor number of visits $\left(\mathrm{F}_{3,10}=0.74\right.$, $P=0.55$ ) varied by colony. Foragers showed a preference for the previously visited feeder $\left(\mathrm{t}_{13}=6.70\right.$, $P<0.0001)$, choosing it over the clean one $65.1 \%$ of the time (range $47.1 \%-76.9 \%$ ). Preference for the visited feeder did not increase with the number of forager visits (linear regression: $\mathrm{F}_{1,12}=1.53$, $\left.P=0.24, r^{2}=0.11\right)$.

Experienced M. quadrifasciata foragers deposit and orient to scent marks with similar frequency as other Melipona (Aguilar and Sommeijer, 2001; Hrncir et al., 2004). Given the same preference by newly-recruited $M$. panamica (Nieh, 2004), it is likely that both experienced and newly arriving $M$. quadrifasciata foragers orient towards nestmates' scent marks within a patch. Use of scent marks to identify rewarding food sources is likely ancestral to the corbiculate bees; bumblebees and honeybees also show attraction to ad libitum feeders (reviewed in Saleh and Chittka, 2006). Melipona 
quadrifasciata foragers may use context to interpret scent marks, with bees learning to associate marks with an ad libitum or a depleting resource. Bumblebees appear to use "footprints" in this manner (Saleh and Chittka, 2006), avoiding slowlyreplenishing food sources on which recent visitors have walked. Footprints secreted from the claw retractor tendon are the source of attractive marks in M. seminigra (Jarau et al., 2004), thus may be used by our study species. Further work is required to identify the source and properties of M. quadrifasciata scent marks.

\section{ACKNOWLEDGEMENTS}

We thank Haley Hunter-Zinck, Angie Kemsley, Ronaldo Zucchi for field assistance and lab space. Work was supported by NSF IBN 0316697, Belkin Fellowship, UCSD Chancellor's Fellowship and the UCSD Division of Biology.

Note scientifique sur le dépôt par les butineuses d'abeilles sans aiguillon de marques odorantes attractives qui ne donnent pas d'indication sur la source de nourriture.

Eine wissenschaftliche Notiz: Sammlerinnen einer Stachellosen Biene ohne Futterquellenkommunikation hinterlassen attraktive Duftmarken.

\section{REFERENCES}

Aguilar I., Sommeijer M. (2001) The deposition of anal excretions by Melipona favosa foragers (Apidae: Meliponinae): behavioural observations concerning the location of food sources, Apidologie 32, 37-48.

Giurfa M., Núñez J.A. (1992) Honeybees mark with scent and reject recently visited flowers, Oecologia 89, 113-117.

Hrncir M., Jarau S., Zucchi R., Barth F.G. (2004) On the origin and properties of scent marks deposited at the food source by a stingless bee, Melipona seminigra, Apidologie 35, 3-13.

Jarau S., Hrncir M., Zucchi R., Barth F.G. (2000) Recruitment behavior in stingless bees, Melipona scutellaris and $M$. quadrifasciata. I. Foraging at food sources differing in direction and distance, Apidologie 31, 81-91.

Jarau S., Hrncir M., Ayasse M., Schultz C., Francke W., Zucchi R., Barth F.G. (2004) A stingless bee (Melipona seminigra) marks food sources with a pheromone from its claw retractor tendons, J. Chem. Ecol. 30, 793-804.

Kerr W.E. (1994) Communication among Melipona workers (Hymenoptera: Apidae), J. Insect Behav. 7, 123-128.

Nieh J.C. (2004) Recruitment communication in stingless bees (Hymenoptera, Apidae, Meliponini), Apidologie 35, 159-182.

Saleh N., Chittka L. (2006) The importance of experience in the interpretation of conspecific chemical signals, Behav. Ecol. Sociobiol. 61, 215-220.

Wilms J., Eltz T. (2008) Foraging scent marks of bumblebees: footprint cues rather than pheromone signals, Naturwissenschaften 95, 149-153. 